\title{
EFFECT OF CARBONISATION ON THE MECHANICAL PROPERTIES AND HYDRATION OF MAGNESIUM AMMONIUM PHOSPHATE CEMENT
}

\author{
GAO YUXIN*,**, YU BAOYING*,**, "KONG YANING**, CHENG BAOJUN**, YANG WEN**, \\ WU JING***, ZHU XIAOLIANG** \\ *College of Materials Science and Engineering, Chongqing University, Chongqing 400045, China \\ **China West Construction Academy of Building Materials, Chengdu 610200, China \\ ***School of Materials Science and Engineering, Wuhan Textile University, Wuhan 400045, China \\ ${ }^{\#}$ E-mail: kongyaning@escec.com
}

Submitted July 21, 2021; accepted September 10, 2021

\begin{abstract}
Keywords: Magnesium Ammonium Phosphate Cement, Fly Ash, Carbonisation, Mechanical Property, Hydration
The flexural strength and compressive strength of a magnesium ammonium phosphate cement and a magnesium ammonium phosphate cement-fly ash composite binder before and after carbonisation were compared, and the effects of carbonisation on its hydration and microstructure were studied. The results show that carbonisation can transform the amorphous phase and dittmarite into crystalline struvite, and refine the pore size of more than $1000 \mathrm{~nm}$, so as to improve the strength of the magnesium ammonium phosphate cement. Fly ash inhibits the hydration of magnesium oxide in the magnesium ammonium phosphate cement, thus greatly increasing the porosity, resulting in the reduction of strength; however, carbonisation curing promotes the hydration of magnesium oxide in the magnesium ammonium phosphate cement-fly ash composite binder, and increases the content of the crystalline struvite. Carbonisation reduces the porosity by refining the pore structure, and consequently improves the flexural and compressive strength of the magnesium ammonium phosphate cement-fly ash composite binder.
\end{abstract}

\section{INTRODUCTION}

Magnesium phosphate cement (MPC) is a kind of special cement which is made of magnesium oxide and phosphate through an acid-alkali reaction [1]. It mainly includes ammonium magnesium phosphate cement and potassium magnesium phosphate cement, which are commonly used in engineering repairs, pavement emergency repairs and other fields [2-4]. As a supplement to the traditional cement concrete repair materials, the durability of this material in service has attracted more and more attention of relevant scholars [5]. Carbonisation performance is an important factor affecting the durability of materials in service. Jeon I. $\mathrm{K}$. et al. studied the effect of carbonisation curing on the hydration and microstructure of a potassium magnesium phosphate cement concrete prepared by potassium dihydrogen phosphate [6]. The results show that compared with a non-carbonated potassium magnesium phosphate cement concrete, the $28 \mathrm{~d}$-strength of the carbonated potassium magnesium phosphate cement concrete increased from 25.2 $\mathrm{MPa}$ to $38.6 \mathrm{MPa}$, and the 60d-strength increased from 29.1 MPa to $46.5 \mathrm{MPa}$. This is because a fibrous magnesium carbonate is generated after the carbonisation of the potassium magnesium phosphate cement. The carbonisation product can fill the pores of the hardened body and refine the pore structure, so as to improve the strength. According to the research of Yang Jianming et al., the phases of magnesium phosphate cement after hardening are mainly struvite and magnesium oxide, and the $\mathrm{pH}$ is about 8.7. Alkaline materials will undergo an acid-base neutralisation reaction with carbon dioxide in air, resulting in changes to the pore structure and carbonisation properties [7].

Adding an admixture to magnesium phosphate cement is an effective measure to adjust the performance of the magnesium phosphate cement and reduce the preparation cost. Among them, fly ash is the most commonly used admixture for preparing magnesium phosphate cement with high properties [8-11]. The research of Lin Wei et al. shows that fly ash can play an active effect, morphological effect and micro-aggregate effect in a magnesium phosphate cement system [12]. Adding $40 \%$ fly ash can improve the compressive strength of magnesium phosphate cement by $19 \%$. At present, the research on the fly ash influence on the durability of magnesium phosphate cement mainly focuses on water resistance, corrosion resistance, volume stability and so on. Tan Yongshan and Li Yue studied the effect of fly ash on the water resistance and seawater corrosion resistance of potassium magnesium phosphate cement $[13,14]$. The results show that when the content of fly ash is $40 \%$, the rod hydration product crystal is embedded in the middle of the fly ash particles, the matrix structure is 
dense, and its water resistance and seawater corrosion resistance are significantly improved, which can meet the repair requirements of open-air environment and seaport engineering. Chang Yuan et al. studied the effect of fly ash content on the volume stability of magnesium phosphate cement [15]. The results show that when the fly ash content is increased, the dry shrinkage of the magnesium phosphate cement increases. The effect of the fly ash on the carbonisation resistance of magnesium phosphate cement has not been found.

Based on the above analysis, existing studies have proven that carbonisation is conducive to the refinement of the pore structure and the improvement of the mechanics of magnesium potassium phosphate cements, but the effect of carbonisation on magnesium ammonium phosphate cement is still unknown. Compared with potassium magnesium phosphate cement, the strength of magnesium ammonium phosphate cement is higher [16]. It is unknown whether the improvement in the strength can help improve the anti-carbonisation ability. Magnesium ammonium phosphate cement will release ammonia during the preparation process, thus changing the pore structure of hardened cement $[17,18]$. The change in the pore structure is found to affect the diffusion rate of carbon dioxide in magnesium ammonium phosphate cement, thus affecting the carbonisation depth. Moreover, compared with magnesium potassium phosphate cement, the cation in the ammonium magnesium phosphate cement changes from $\mathrm{K}^{+}$to $\mathrm{NH}_{4}^{+}$, and it is still unclear whether the change of the cation will affect the type, quantity and morphology of the carbonisation products, thus affecting the pore structure and the development law of the carbonisation strength. In addition, fly ash, as the most commonly used admixture of magnesium ammonium phosphate cement, has a significant impact on the mechanical properties and microstructure, but there is still lack of research on its impact on the carbonisation.

Therefore, this paper studies the mechanical properties of a magnesium ammonium phosphate cement and a magnesium ammonium phosphate cement-fly ash composite system in a carbonisation environment. At the same time, through a micro-analysis, the mechanism of carbonisation of magnesium ammonium phosphate cement and fly ash in the carbonisation process of magnesium ammonium phosphate cement are expounded upon.

\section{MATERIALS AND METHODS}

\section{Raw materials}

Magnesium ammonium phosphate cement is prepared from dead burned magnesium oxide, ammonium dihydrogen phosphate and borax. Dead burned magnesia is prepared by grinding magnesite after high temperature calcination at $1700{ }^{\circ} \mathrm{C}$. The chemical components are shown in Table 1. The specific surface area is $248 \mathrm{~m}^{2} \cdot \mathrm{kg}^{-1}$, the density is $3.20 \mathrm{~g} \cdot \mathrm{cm}^{-3}$, and the $\mathrm{MgO}$ content is $\geq 95.0 \%$. Industrial grade ammonium dihydrogen phosphate $\left(\mathrm{NH}_{4} \mathrm{H}_{2} \mathrm{PO}_{4}\right)$ with a purity of $\geq 99.0 \%$ was used; Borax $\left(\mathrm{Na}_{2} \mathrm{~B}_{4} \mathrm{O}_{7} \cdot 10 \mathrm{H}_{2} \mathrm{O}\right)$, as a retarding component in the magnesium phosphate cement, is a white crystal with a purity of $\geq 99.0 \%$. The fly ash is grade I, with a specific surface area of $450 \mathrm{~m}^{2} \cdot \mathrm{kg}^{-1}$, and its chemical composition is shown in Table 2.

The X-ray diffraction (XRD) patterns of four raw materials are shown in Figure 1. As can be seen from Figure 1, the main component of the dead burned magnesium oxide is $\mathrm{MgO}$.

Ammonium dihydrogen phosphate is composed of crystalline and amorphous phases. The main component of borax is sodium borate, and the crystalline phases of fly ash are mullite and quartz.

\section{Mix design}

The mix proportion design of the test magnesium phosphate cement and magnesium phosphate cement fly ash system is shown in Table 3. Two series were used in the test, P1 and P2. Each series corresponds to two curing methods, namely normal curing (P1-1, P2-1) and carbonisation curing (P1-2, P2-2). The experimental water cement ratio is 0.12 . The $\mathrm{P} 1$ and $\mathrm{P} 2$ powder samples before mixing without water are represented by P1-0 and P2-0.

Table 1. Chemical composition of the dead burned magnesia (wt. \%).

\begin{tabular}{ccccccc}
\hline Oxide & $\mathrm{MgO}$ & $\mathrm{SiO}_{2}$ & $\mathrm{CaO}$ & $\mathrm{Al}_{2} \mathrm{O}_{3}$ & $\mathrm{Fe}_{2} \mathrm{O}_{3}$ & Others \\
\hline Content & 96.88 & 0.58 & 1.26 & 0.10 & 0.51 & 0.18
\end{tabular}

Table 2. Chemical composition of the fly ash (wt. \%).

\begin{tabular}{ccccccccc}
\hline Oxide & $\mathrm{MgO}$ & $\mathrm{SiO}_{2}$ & $\mathrm{CaO}$ & $\mathrm{Al}_{2} \mathrm{O}_{3}$ & $\mathrm{Fe}_{2} \mathrm{O}_{3}$ & $\mathrm{TiO}_{2}$ & $\mathrm{SO}_{3}$ & $\mathrm{LOI}$ \\
\hline Content & 1.32 & 49.03 & 4.54 & 29.21 & 6.51 & 1.88 & 1.03 & 4.97 \\
\hline
\end{tabular}




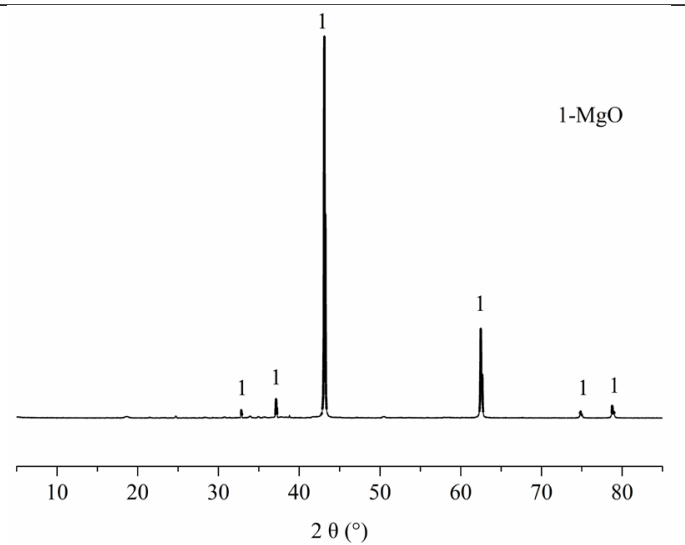

a) Over-fired magnesia

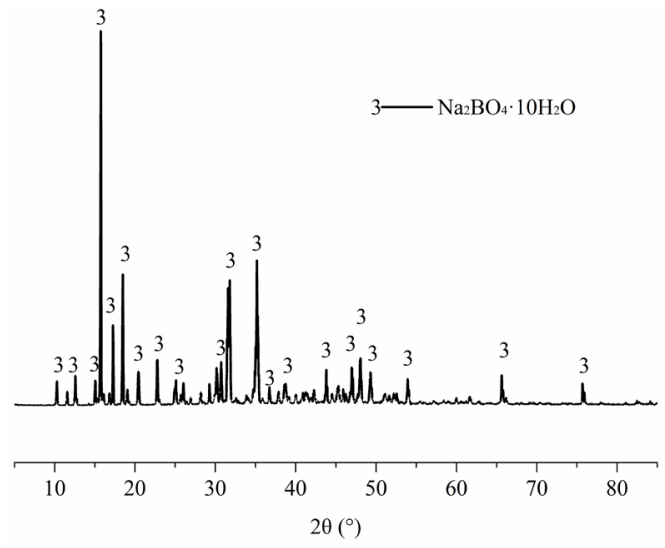

c) Sodium tetraborate decahydrate

Figure 1. X-ray diffraction analysis of the raw materials

Table 3. Mix proportion of the magnesium phosphate cement (wt. \%).

\begin{tabular}{lcccc}
\hline NO. & $\begin{array}{c}\text { Ammonium } \\
\text { dihydrogen } \\
\text { phosphate }\end{array}$ & $\begin{array}{c}\text { Over-fired } \\
\text { magnesia }\end{array}$ & Borax & Fly ash \\
\hline P1 & 23.5 & 70.5 & 6.0 & $/$ \\
P2 & 20.0 & 60.0 & 6.0 & 14
\end{tabular}

Sample preparation and test methods

\section{Sample preparation and curing}

The powder was poured into the mortar mixer for low-speed mixing for $30 \mathrm{~s}$, then water was added for rapid mixing for $90 \mathrm{~s}$, and then the slurry was poured into the mould for forming. The size of the test piece was $40 \mathrm{~mm} \times 40 \mathrm{~mm} \times 160 \mathrm{~mm}$. The test piece was demoulded after 2 hours, and the demoulded test piece was cured for 7 days under normal curing (a temperature of $20 \pm 5{ }^{\circ} \mathrm{C}$ and a relative humidity of $60 \pm 5 \%$ ). Then, some specimens were placed in the carbonisation box for curing. The carbonisation curing temperature was $20 \pm 5{ }^{\circ} \mathrm{C}$, the humidity was $70 \pm 5 \%$, and the $\mathrm{CO}_{2}$ concentration was $20 \pm 3 \%$.

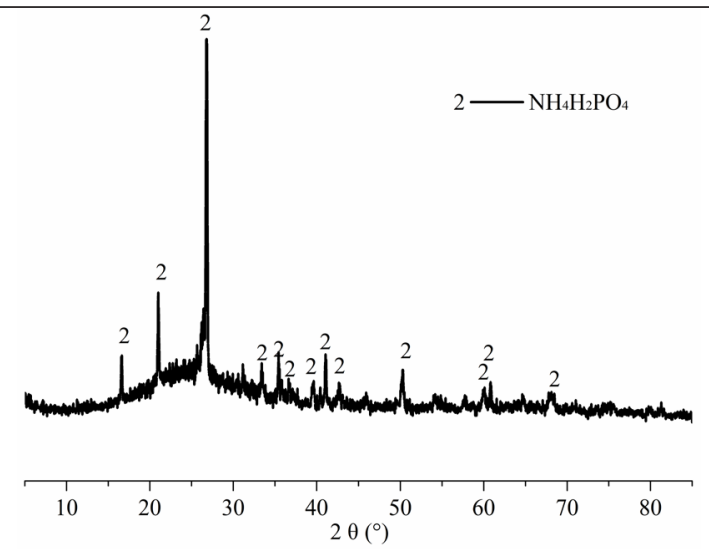

b) Ammonium dihydrogen phosphate

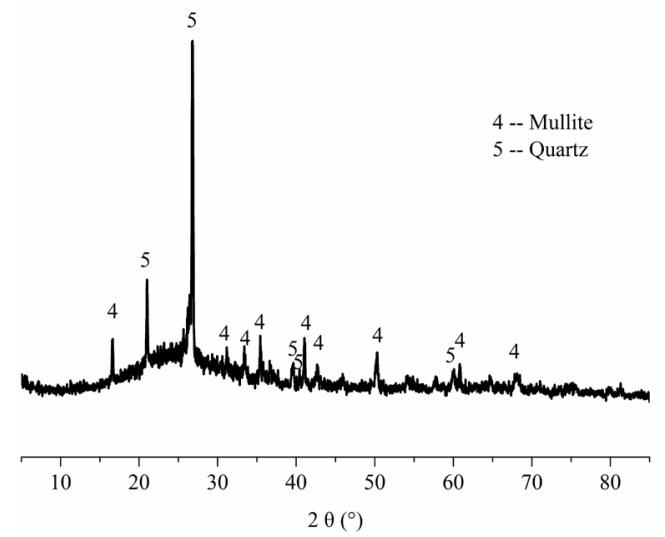

d) Fly ash

\section{Test methods}

The mechanical properties were tested by a tye$300 \mathrm{~d}$ cement mortar flexural and compressive testing machine. The loading rate of the flexural strength was $0.05 \mathrm{kN} \cdot \mathrm{s}^{-1}$ and the loading rate of the compressive strength was $2.4 \mathrm{kN} \cdot \mathrm{s}^{-1}$. The surface samples that were cured normally for $63 \mathrm{~d}$ and carbonisation ones cured for $56 \mathrm{~d}$ were used for the micro-analysis.

An X-ray diffraction (XRD) analysis was conducted using a Bruker AXS D8 X-ray diffractometer. A continuous scanning mode with a rate of $3^{\circ} \cdot \mathrm{min}^{-1}$ was adopted, and the test range was $5-85^{\circ}$. The Rietveld method was used for the quantitative analysis. The internal standard was $\mathrm{Al}_{2} \mathrm{O}_{3}$. The content was $20 \%$.

A mercury injection analysis (MIP) was carried out with an autopore-iv-9500 produced by micromeritics. The test pressure range was $0.1-61000$ psia.

The fracture morphology was observed by an FEI inspect F50 scanning electron microscope, and an energy-dispersive X-ray spectroscopy (EDS) analysis was carried out by EDAX super octane equipment. Before the test, the sample was sprayed with gold in a vacuum. 


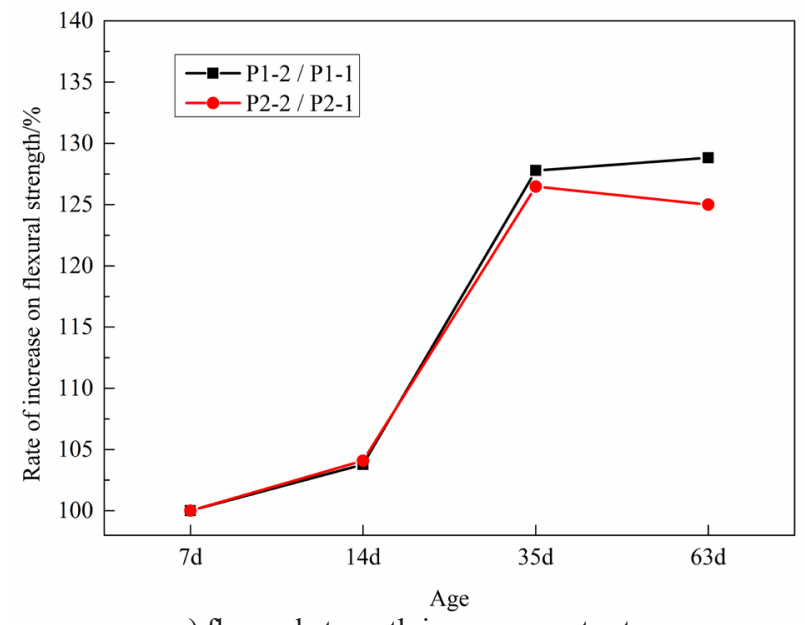

a) flexural strength improvement rate

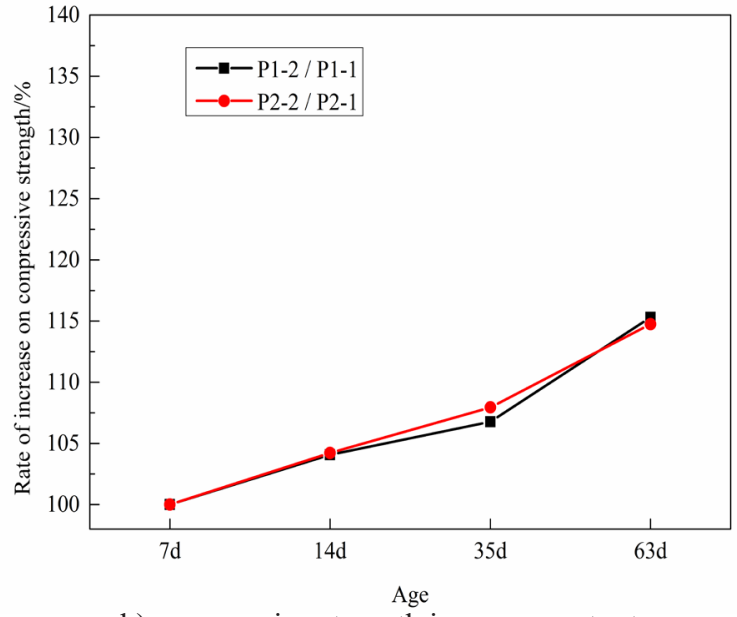

b) compressive strength improvement rate

Figure 2. Increase percentage of the MPC strength after carbonisation curing.

\section{RESULTS AND DISCUSSION}

Mechanical properties

The flexural and compressive strength of magnesium ammonium phosphate cement under different curing conditions at each age are shown in Table 4 and Table 5. It can be seen from Table 4 that the flexural strength of the magnesium ammonium phosphate cement continues to improve under normal curing; at the same time, the flexural strength of magnesium ammonium phosphate cement after carbonisation curing is higher than that of the natural curing. Under normal curing, the addition of fly ash reduces the early flexural strength of the magnesium ammonium phosphate cement, but improves the later flexural strength. After carbonisation, the flexural strength of the magnesium ammonium phosphate cement mixed with the fly ash is also improved. The above shows that carbonisation is helpful in improving the flexural strength of magnesium ammonium phosphate cements.

It can be seen from Table 5 that, under normal curing, the compressive strength of the magnesium phosphate cement continues to increase with the extension of the age. After carbonisation, the compressive strength of the magnesium ammonium phosphate cement at the same age is higher than that cured under standard conditions. Fly ash can reduce the early and late compressive strength of magnesium ammonium phosphate cements under a normal curing environment. However, after carbonisation, the compressive strength of the magnesium ammonium phosphate cement mixed with fly ash is still higher than that of the non-carbonised specimens. The above shows that carbonisation is helpful in improving the compressive strength of magnesium ammonium phosphate cements.

In order to further clarify the effect carbonisation curing has on the mechanical properties of the magnesium ammonium phosphate cement, the flexural and compressive strength improvement rate after carbonisation is plotted as shown in Figure 2. From Figure 2a, it can be seen that the flexural strength improvement rate of $\mathrm{P} 1$ continues to increase after carbonisation and tends to be stable after 28 days of carbonisation; after carbonisation, the improvement rate of P2 increased first and then decreased slightly, reaching its peak at 28 days of carbonisation. From Figure $2 b$, it can be seen that the compressive strength improvement rates of $\mathrm{P} 1$ and $\mathrm{P} 2$ after carbonisation increase with an increase in the carbonisation time.

Table 4. Flexural strength of the MPC at different ages (MPa).

P1-1

(average value \pm S.D.)
P1-2
P2-1

\begin{tabular}{lcccc} 
& (average value \pm S.D.) & (average value \pm S.D.) & (average value \pm S.D.) & (average value \pm S.D.) \\
\hline $7 \mathrm{~d}$ & $9.7 \pm 0.25$ & $9.7 \pm 0.25$ & $8.8 \pm 0.35$ & $8.8 \pm 0.35$ \\
$14 \mathrm{~d}$ & $10.6 \pm 0.18$ & $11.0 \pm 0.20$ & $9.8 \pm 0.20$ & $10.2 \pm 0.15$ \\
35d & $10.8 \pm 1.10$ & $13.8 \pm 0.88$ & $10.2 \pm 1.10$ & $12.9 \pm 0.92$ \\
$63 \mathrm{~d}$ & $11.1 \pm 1.24$ & $14.3 \pm 1.05$ & $11.2 \pm 1.34$ & $14.0 \pm 1.08$ \\
\hline
\end{tabular}


Table 5. Compressive strength of the MPC at different ages (MPa).

P1-1

(average value \pm S.D.)
P1-2

(average value \pm S.D.)
P2-1

P2-2 (average value \pm S.D.)

$30.7 \pm 1.04$

$34.6 \pm 0.54$

$39.4 \pm 1.48$

$43.6 \pm 2.20$

$34.4 \pm 1.25$
$38.3 \pm 1.20$
$44.2 \pm 1.24$
$50.5 \pm 2.43$

$33.2 \pm 0.82$

$36.5 \pm 1.51$

$38.0 \pm 1.58$
However, in this study, the hydration degree of the magnesium oxide in P2-1 is $15.1 \%$, lower than P1-1. It shows that fly ash can inhibit the hydration of the magnesium ammonium phosphate cement under natural curing conditions. This is because the magnesium oxide reaction depends on the acidity of the phosphate. Fly ash is alkaline, which reduces the acidity of the phosphate components and inhibits the hydration. At the same time, the struvite and dittmarite contents in P2-1 are lower than those in P1-1. Therefore, compared with P1-1, after adding fly ash, the hydration degree of the magnesium ammonium phosphate cement and cementitious materials used for the hydration are reduced at the same time, so that the strength of the magnesium ammonium phosphate cement-fly ash composite system is lower than that of the magnesium ammonium phosphate cement.

Compared with P2-1, the hydration degree of the magnesium oxide in P2-2 increased from $15.1 \%$ to $19.3 \%$, the struvite content increased from $10.59 \%$ to $13.88 \%$, the dittmarite content decreased and the amorphous phase content increased. Therefore, the carbonisation environment promotes the hydration of the magnesium ammonium phosphate cement-fly ash composite system, and improves the transformation from dittmarite to crystalline struvite stone, so as to make the sample strength higher under carbonisation curing.

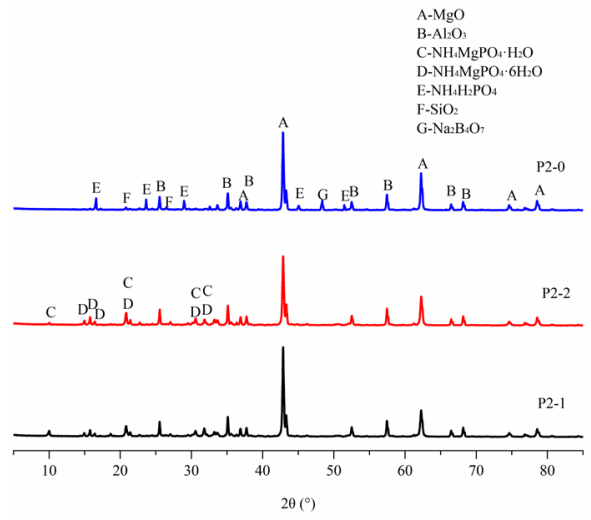

b) X-ray diffraction analysis of the P2 samples

Figure 3. X-ray diffraction analysis of the P1 and P2 samples. 
Effect of carbonisation on the mechanical properties and hydration of magnesium ammonium phosphate cement

Table 6. The content of each phase in the P1 and P2 samples (wt. \%).

\begin{tabular}{cccccccc}
\hline No. & $\mathrm{MgO}$ & $\mathrm{NH}_{4} \mathrm{H}_{2} \mathrm{PO}_{4}$ & $\begin{array}{c}\mathrm{Na}_{2} \mathrm{~B}_{4} \mathrm{O}_{7} \\
\cdot 10 \mathrm{H}_{2} \mathrm{O}\end{array}$ & $\begin{array}{c}\mathrm{SiO}_{2} \\
\mathrm{NH}_{4} \mathrm{MgPO}_{4} \\
6 \mathrm{H}_{2} \mathrm{O}\end{array}$ & $\begin{array}{c}\mathrm{NH}_{4} \mathrm{MgPO}_{4} \\
\cdot \mathrm{H}_{2} \mathrm{O}\end{array}$ & Amorphous phase \\
\hline $\mathrm{P} 1-0$ & 60.63 & 11.80 & 3.27 & $/$ & $/$ & $/$ & 24.30 \\
$\mathrm{P} 1-1$ & 45.90 & $/$ & 2.70 & $/$ & 13.00 & 13.60 & 24.80 \\
$\mathrm{P} 1-2$ & 51.00 & $/$ & 1.60 & $/$ & 17.20 & 7.90 & 23.30 \\
$\mathrm{P} 2-0$ & 47.81 & 6.50 & 3.09 & 5.89 & $/$ & $/$ & 36.71 \\
$\mathrm{P} 2-1$ & 40.60 & $/$ & 0.60 & 5.01 & 10.59 & 9.50 & 33.70 \\
$\mathrm{P} 2-2$ & 38.60 & $/$ & 0.80 & 5.12 & 13.88 & 3.90 & 37.70 \\
\hline
\end{tabular}

\section{MIP analysis}

The cumulative pore size curve and pore size distribution curve of the magnesium ammonium phosphate cement and magnesium ammonium phosphate cement-fly ash composite system before and after carbonisation are shown in Figure 4. It can be seen from Figure 4 that the cumulative mercury input of $\mathrm{P} 1-1$ is slightly lower than that of the P1-2 sample, indicating that the porosity increases slightly after carbonisation. From the pore size distribution curve, although the number of $100-1000 \mathrm{~nm}$ pores of P1-1 is lower than that of P1-2, the number of $1000-10000 \mathrm{~nm}$ pores of P1-1 is significantly higher than that of P1-2. Combined with the XRD analysis, the carbonisation will inhibit the hydration of the magnesium ammonium phosphate cement and slightly increase the overall porosity, but, at the same time, it will promote the formation of crystalline struvite stone and reduce the macropore content. The decrease in the macropore content leads to an increase in the strength after carbonisation. Compared with P2-1, the porosity of the P2-2 sample after carbonisation is significantly smaller. Combined with the XRD quantitative analysis, it can be seen that carbonisation curing is conducive to the hydration of magnesium oxide in the magnesium ammonium phosphate cementfly ash composite system, promoting an increase in the crystalline hydration products and amorphous hydration products, so as to reduce the porosity and improve the strengtht.

Compared with P1, after adding fly ash, the peak value of the pore size distribution curve shifts to the left whether it is natural curing or carbonisation curing, indicating that after adding fly ash, the number of pores above $1000 \mathrm{~nm}$ can be reduced, so as to refine the pore structure. At the same time, compared with $\mathrm{P} 1$, the porosity of the P2 composite system is greatly improved, resulting in a decrease in strength.

\section{Fracture morphology}

The fracture morphology of the magnesium ammonium phosphate cement before and after carbonisation is shown in Figure 5. The hardened body of the normal cured magnesium ammonium phosphate

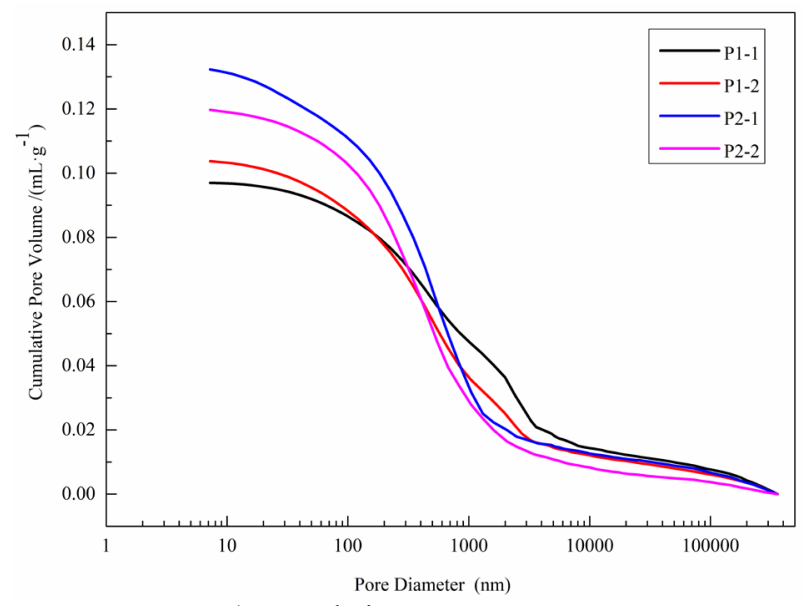

a) Cumulative aperture curve

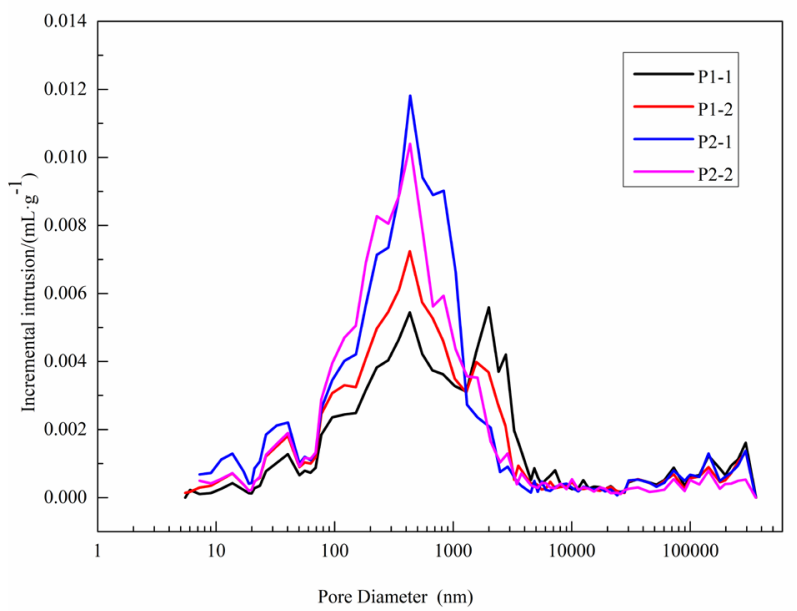

b) Pore size distribution curve

Figure 4. Pore structure analysis curve.

cement has a dense structure, and the struvite stone is tightly wrapped with unhydrated magnesium oxide; the fly ash particle surface is smooth, but it is closely combined with hydration products, indicating that the fly ash mainly plays the role of filling and as a microaggregate. After carbonisation, some hydration products of the magnesium ammonium phosphate cement will form flake and needle rod hydration products, which overlap each other and are still closely combined. 
Gao Y., Yu B., Kong Y., Cheng B., Yang W., Wu J., Zhu Y.

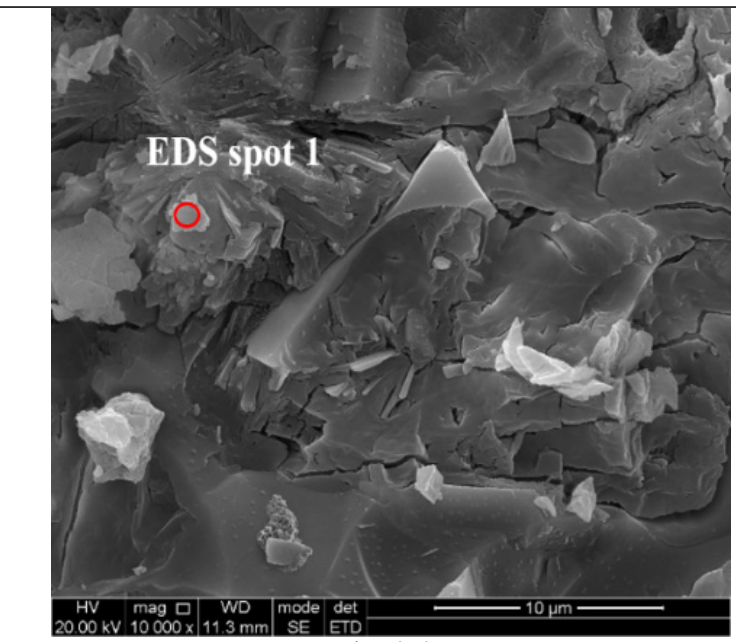

a) $\mathrm{P} 1-1$

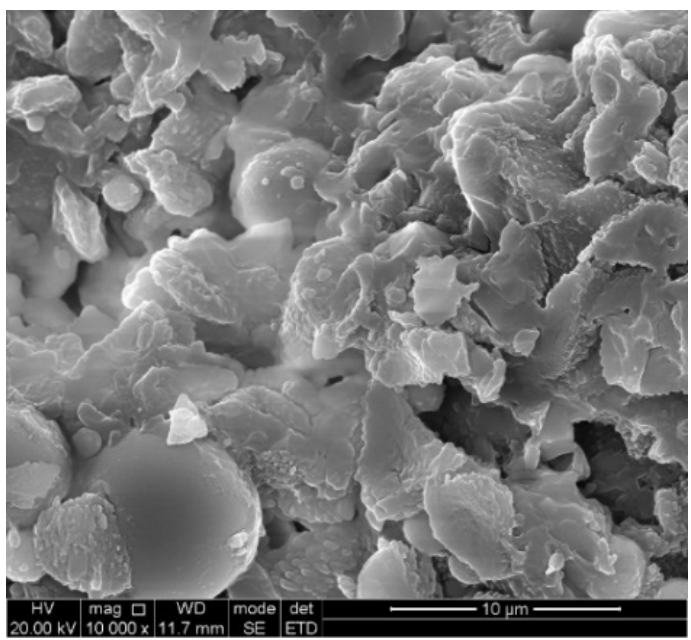

c) P2-1

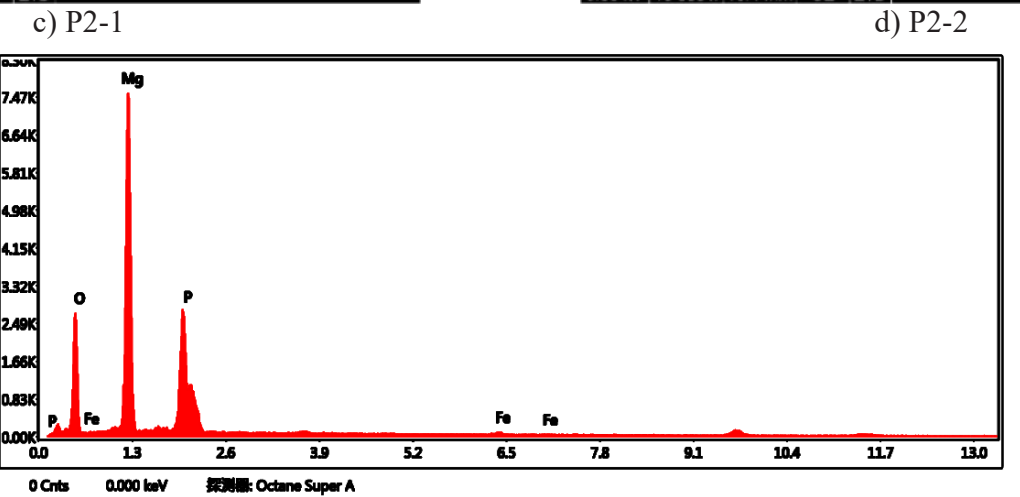

e) Energy spectrum of EDS spot 1

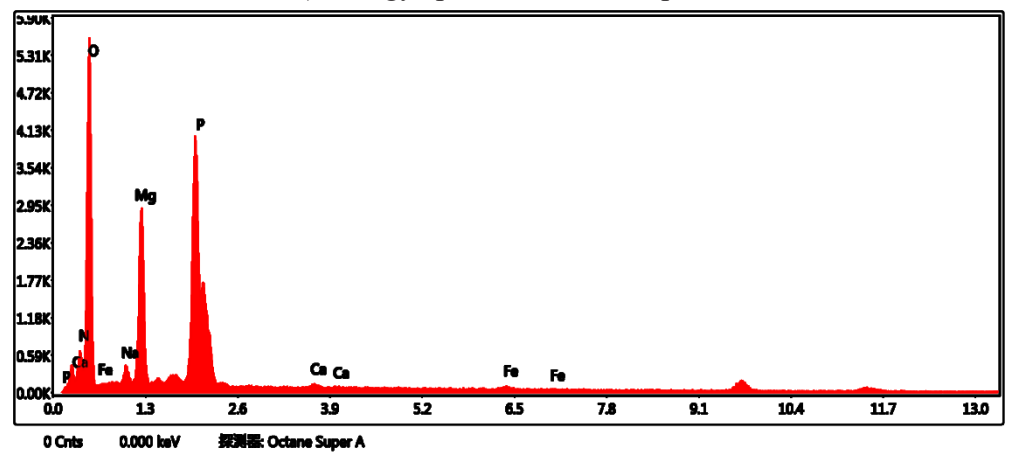

f) Energy spectrum of EDS spot 2

Figure 5. SEM-EDS diagram of the magnesium phosphate cement before and after carbonisation. 
Effect of carbonisation on the mechanical properties and hydration of magnesium ammonium phosphate cement

Table 7. Results of the energy spectrum analysis.

\begin{tabular}{ccccccc}
\hline No. & \multicolumn{7}{c}{ Atomic fraction (\%) } \\
\cline { 2 - 7 } & $\mathrm{O}$ & $\mathrm{Na}$ & $\mathrm{Mg}$ & $\mathrm{P}$ & $\mathrm{Ca}$ & $\mathrm{Fe}$ \\
\hline $\mathrm{P} 1-2$ & 69.52 & 2.32 & 12.03 & 15.35 & 0.34 & 0.44 \\
$\mathrm{P} 1-1$ & 44.08 & $/$ & 37.2 & 18.14 & $/$ & 0.59 \\
\hline
\end{tabular}

The differences in the products before and after carbonisation are compared and analysed by EDS, and the results are shown in Table 7 . It can be seen that carbonisation reduces the magnesium-phosphorus ratio in the product. This may be due to the change in the solution's $\mathrm{pH}$ after the carbon dioxide dissolves in the pore solution, which reduces the magnesium-phosphorus ratio of the hydration product and forms a needle rod or flake crystal morphology.

\section{CONCLUSION}

By comparing the mechanical properties and microstructure of a magnesium ammonium phosphate cement system and a magnesium ammonium phosphate cement-fly ash composite system under normal curing conditions and carbonisation curing conditions, this paper defines the development law of carbonisation on the mechanical properties of the magnesium ammonium phosphate cement and its composite system with fly ash, and expounds upon the carbonisation mechanism. The specific conclusions are as follows:

(1) Carbonisation curing will inhibit the hydration of magnesium oxide and improve the porosity, but, at the same time, it will reduce the amorphous phase and dittmarite content in the hydration products, increase the crystalline struvite stone content and refine the pore content above $1000 \mathrm{~nm}$, so as to improve the flexural and compressive strength of the magnesium ammonium phosphate cement.

(2) Fly ash will greatly inhibit the hydration of $\mathrm{MgO}$, increase the porosity of the magnesium ammonium phosphate cement, and reduce the flexural and compressive strength of the magnesium ammonium phosphate cement; carbonisation can reduce the inhibition extent of the fly ash on the $\mathrm{MgO}$ hydration in the magnesium ammonium phosphate cement-fly ash composite system, so as to reduce the porosity, refine the pore size distribution, and improve the flexural and compressive strength of the magnesium ammonium phosphate cement fly ash composite system.

\section{Acknowledgment}

This project is funded by the 2020 national key $R$ \& D plan "solid waste recycling" key special project (2019YFC1907200), the State Natural Science Fund project (52078394); Sichuan Science and Technology Program (2021YJ0530).

\section{REFERENCES}

1. Yu B., Zhou J., Cheng B., Yang W. (2021): Compressive strength development and microstructure of magnesium phosphate cement concrete. Construction and Building Materials, 283, 122585. Doi: 10.1016/j.conbuildmat.2021.122585

2. Arora A., Singh B., Kaur P. (2019): Novel material ie magnesium phosphate cement (MPC) as repairing material in roads and buildings. Materials Today: Proceedings, 17, 70-76. Doi: 10.1016/j.matpr.2019.06.402

3. Park J. W., Ann K. Y. (2017): Fundamental Properties of $\mathrm{MgO}$ Base Ceramic Mortar for Concrete Repair Material. Journal of the Korea Concrete Institute, 29(4), 407-413. Doi: 10.4334/JKCI.2017.29.4.407

4. Zhang W. (2018): Durability of repaired concrete pavement surface defects with MPC materials. Modern Materials Science and Technology, 1(1). Doi: 10.18063/mmst. v1i1.764

5. Liu K., Jiang F., Zhang C., Zhang B., Li D. (2012). Failure mechanism of dipotassium hydrogen phosphate modified magnesia-phosphate cements under water curing condition. Journal of the Chinese Ceramic Society, 40(12), 16931698.

6. Jeon I. K., Qudoos A., Kim H. G. (2021): Influence of carbonation curing on hydration and microstructure of magnesium potassium phosphate cement concrete. Journal of Building Engineering, 38, 102203.doi: 10.1016/ j.jobe.2021.102203

7. Yang J., Qian C., Xun Y. et al. (2009): Mechanical Performance of glass fiber reinforced magnesia. $J$ Build Mater, 12(5), 590-594.

8. Ribeiro D. V., Paula G. R., Morelli M. R. (2019): Effect of boric acid content on the properties of magnesium phosphate cement. Construction and Building Materials, 214, 557-564. doi: 10.1016/j.conbuildmat.2019.04.113

9. Ding Z, Li Z. (2005): High-early-strength magnesium phosphate cement with fly ash. ACI Materials Journal, 102(6), 375-381.

10. Zhao S., Yan H., Wang H., et, al. (2017): Effect of Fly Ash Content on Hydration Kinetics of Magnesium Potassium Phosphate Cement. Chinese Journal of Materials Research, 31(11), 839-846. Doi: 10.11901/1005.3093.2017.274

11. Wang Q, Qian J., Qin J, et al. (2013): Effect of temperature on setting time and strength development of magnesiaphosphate cement. Journal of the Chinese Ceramic Society, 41(11), 1493-1498.

12. Lin W., Sun W., Li Z. (2010): Study on the effects of fly ash in magnesium phosphate cement. J. Build. Mater., 13(6),716-721.

13. Tan Y. S., Yu H. F., Li Y., Dong J. M. (2014): Preparation of Fly Ash Magnesium Phosphate Cement Using Byproduct Magnesium Oxide Containing Boron from Salt Lake. 
Gao Y., Yu B., Kong Y., Cheng B., Yang W., Wu J., Zhu Y.

Journal of the Chinese Ceramic Society, 42(11), 13621369.

14. Li Y., Shi T., Sun J. (2015): Experimetal Study on the Performance of Magnesium Phosphate Cement in Alkali. $J$. Build. Mater., 16(6),1060-1064.

15. Chang Y., Shi C., Yang N., Yang J. (2014): Research progresses on durability of magnesium phosphate cement based materials. Journal of the Chinese Ceramic Society, 42(4), 486-493. Doi: 10.7521/j.issn.04545648.2014.04.11

16. Qin J. (2019). Study on Preparation and mechanical behavior of ultra-high strength magnesium phosphate cement composites (in Chinese, dissertation). Chongqing, Chongqing University.
17. Vandeperre L. J., Al-Tabbaa A. (2007): Accelerated carbonation of reactive $\mathrm{MgO}$ cements. Advances in Cement Research, 19(2), 67-79. Doi: 10.1680/adcr.2007.19.2.67

18. Yang J., Tang Q., Wu Q., Li X., Sun Z. (2017): The effect of seawater curing on properties of magnesium potassium phosphate cement. Construction and Building Materials, 141, 470-478.doi: 10.1016/j.conbuildmat.2017.02.057

19. Sun H., Zeng L., Peng T. (2021): Research Status and Progress of High-value Utilization of Coal Fly Ash. Materials Reports, 35(3), 3010-3015. 